\title{
ANÁLISE DA FRAGILIDADE AMBIENTAL E DAS CONDIÇÕES SOCIAIS DA MESORREGIÃO DA MATA PARAIBANA: SUBSÍDIOS PARA O PLANEJAMENTO DA REGIÃO COSTEIRA
}

\author{
Vinícius Genuino $^{(\mathrm{a})}$, Camila Cunico ${ }^{(\mathrm{b})}$, Marciel Lohmann ${ }^{(\mathrm{c})}$ \\ (a) Graduando do Departamento de Geociências, Universidade Federal da Paraíba, genuinovini@ yahoo.com.br \\ (b) Professora do Departamento de Geociências, Universidade Federal da Paraíba, camilacunico@ yahoo.com.br \\ (c) Professor do Departamento de Geociências, Universidade Estadual de Londrina, \\ marciel_lohmann@yahoo.com.br
}

\section{Eixo: GEOTECNOLOGIAS E MODELAGEM ESPACIAL EM GEOGRAFIA FÍSICA}

\begin{abstract}
Resumo
Os estudos de fragilidade ambiental apresentam-se como uma possibilidade de compreensão integrada do ambiente físico e dos processos antrópicos atuantes diante das mudanças atuais no espaço geográfico. Acentua-se a relevância do entendimento das relações sociedade-natureza, tanto pelo lado de suas contradições como pelo lado das suas interrelações de dependência e funcionalidades. Assim, a presente pesquisa, aplicada na Mesorregião da Mata Paraibana, busca auxiliar nos estudos de análise e planejamento de zonas costeiras utilizando-se, de maneira adaptadada a realidade da área de estudo, a metodologia de Ross $(1994$; 1995) e Becker e Egler (1996). A escolha de tais metodologias justifica-se em função do enorme potencial que os estudos de fragilidade apresentam como instrumentos de auxílio ao planejamento e gestão ambiental.
\end{abstract}

Palavras chave: Geoprocessamento; Análise Ambiental; Planejamento Socioambiental;

\section{Introdução}

Diante do aumento da conscientização ambiental atual, a problemática ambiental que envolve diretamente as relações sociedade-natureza tem sido recorrente em diversas plataformas do conhecimento. Desta forma, estudos voltados à fragilidade ambiental e análise das condições sociais têm destacado-se devido à indispensabilidade de estudos sobre os impactos ambientais, oriundos das atividades humanas, principalmente. Em acordo com isso Ross et al. (2006), explicam que as modificações na dinâmica dos ecossistemas interferem diretamente na intensidade dos fluxos de energia e matéria entre as componentes e afeta, portanto, as interações e interdependências, e seu desenvolvimento.

Esses estudos são importantes por oferecer a possibilidade de abrandar os impactos gerados, assimilar os sistemas ambientais e (re)pensar possibilidades de gestão dessas áreas de estudo. Como ressalta Dias et al. (2015), quando afirmam que cada vez mais não se pode pensar no espaço de forma fragmentada, visto que compreender as mudanças ambientais vai além de sua origem natural, pois a influência antrópica é de grande importância para análise dos elementos da paisagem. 


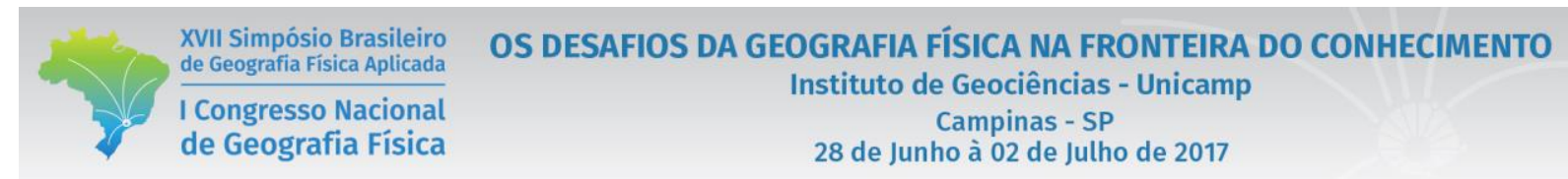

Com isso, o corrente artigo tem como finalidade discutir e identificar os diferentes graus de fragilidade existentes na região costeira do Estado da Paraíba e suas respectivas análises, compreendendo que o estudo da fragilidade ambiental é aplicado como técnica de planejamento, avaliação da evolução e adaptação do sistema natural às novas condições impostas pelo homem (ROSS, et al; 2006). Empregandose a proposta metodológica de Ross $(1994,1995)$, que se utiliza do conceito de Unidades Ecodinâmicas de Instabilidade Potencial e de Instabilidade Emergentes, divididas por grau de fragilidade, como também a análise das condições sociais da área de estudo, por meio dos modelos propostos por Becker e Egler (1996), é que a pesquisa se aplica.

O estudo proposto desenvolve-se na Zona da Mata Paraibana, principal mesorregião do Estado (Figura 1). A mesorregião da Mata Paraibana localiza-se no extremo leste do território estadual, zona costeira, sendo composta por 30 municípios, incluindo a capital, João Pessoa, estando estes subdivididos em quatro microrregiões. Essa mesorregião é de extrema importância econômica e populacional, onde a partir disso é que se destaca a importância do estudo dessa área, visto que historicamente foi onde deu-se início aos fluxos populacionais no Estado, iniciando a urbanização. Os avanços do tecido urbano combinado com os aspectos físico-naturais trazem a necessidade do conhecimento dessas fragilidades para fins de planejamento e gestão geoambiental.

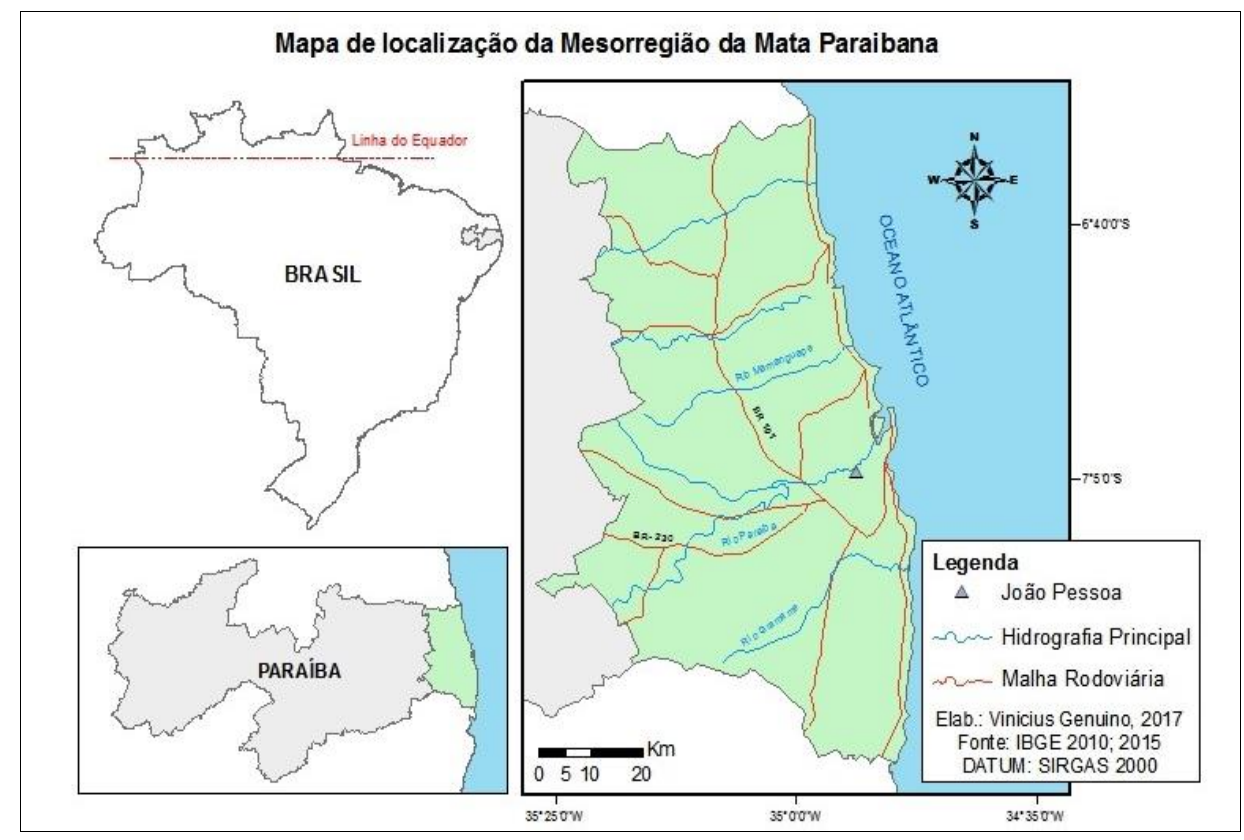

Figura 1 - Localização da área de estudo. 


\section{Materiais e Métodos}

Tendo em vista que na Paraíba não existe um mapeamento sistematizado das variáveis em uma única escala, os dados temáticos foram trabalhados com a melhor escala disponível para cada tema. A área estudada é compreendida por duas imagens do Banco de Dados Geomorfométricos do Brasil, datadas de 2010, junto ao Instituto Nacional de Pesquisas Espaciais, as quais são: 06S36_e 07S36_. Essas imagens possuem resolução de 90 metros, e foram utilizadas para elaboração do mapa de clinografia. Já os mapas de geomorfologia, pedologia e uso e cobertura do solo, foram utilizados dados oriundos de levantamentos feitos pela Agência Executiva de Gestão das Águas do Estado da Paraíba (AESA), em 2010.

As metodologias que serão utilizadas para análise da fragilidade ambiental e condições sociais seguem os parâmetros da metodologia de Ross $(1994,1995)$, onde se definem as Unidades Ecodinâmicas Estáveis e Unidades Ecodinâmicas Instáveis, na qual as primeiras referem-se a unidades onde os processos mecânicos atuam de forma lenta e fraca, e suas condições de estabilidade morfodinâmica aconteçam em áreas: de cobertura vegetal fechada, de modo que evite processos morfogênicos; onde a erosão seja moderada, livre de solapamento de rios, vertentes de lenta evolução e incisão violenta de cursos d'água; e ausência de atividade antrópica. Já as Unidades Ecodinâmicas Instáveis referem-se às unidades onde os processos morfogênicos sejam o elemento predominante na dinâmica natural, e que tenha presença de atividade antrópica. Essas classes ainda serão divididas por seu grau de fragilidade, as quais variam entre muito fraca, fraca, média, forte e muito forte, de acordo com cada aspecto natural e sua condição para fragilidade, como pode ser observado na tabela I.

Tabela I - Fatores e elementos de análise para a determinação da fragilidade ambiental. (Org.: Amaral, 2009)

\begin{tabular}{|l|l|}
\hline Fatores de análise para fragilidade ambiental & \multicolumn{1}{c|}{ Elementos } \\
\hline Uso da terra/Cobertura vegetal & $\begin{array}{l}\text { Densidade da cobertura vegetal. Presença de } \\
\text { práticas conservacionistas. Áreas antrópicas. }\end{array}$ \\
\hline Relevo & Tipos de vertentes. Índices de declividade. \\
\hline Solos & $\begin{array}{l}\text { Textura (granulometria). Profundidade. } \\
\text { Permeabilidade/Compactação. }\end{array}$ \\
\hline Clima & Distribuição anual. Densidade pluviométrica. \\
\hline
\end{tabular}

Além dessa, a avaliação das condições sociais das áreas de estudo se dá por meio dos parâmetros de avaliação propostos por Becker e Egler (1996), sob uma necessária adaptação dos parâmetros como em Cunico e Oka-Fiori (2009). A junção dessas metodologias faz com que seja possível manter as especificidades dos recursos naturais e sociais, promovendo ainda sua integração. Assim, esse mecanismo procura executar diversas cartas temáticas utilizadas para propor intervenções, planejamento e gestão, baseando-se na sustentabilidade e legislação ambiental existente. 


\section{Resultados e discussão}

Com os mapas temáticos organizados em prancha, figura 2, é possível perceber que: ao correlacionar a variável uso e ocupação do solo com as demais variáveis, a importância do estudo da mesorregião se reafirma, visto o aglomerado populacional, bem como a presença de um sistema ambiental essencialmente frágil tendo em vista a relação entre o substrato rochoso, o relevo e os solos.

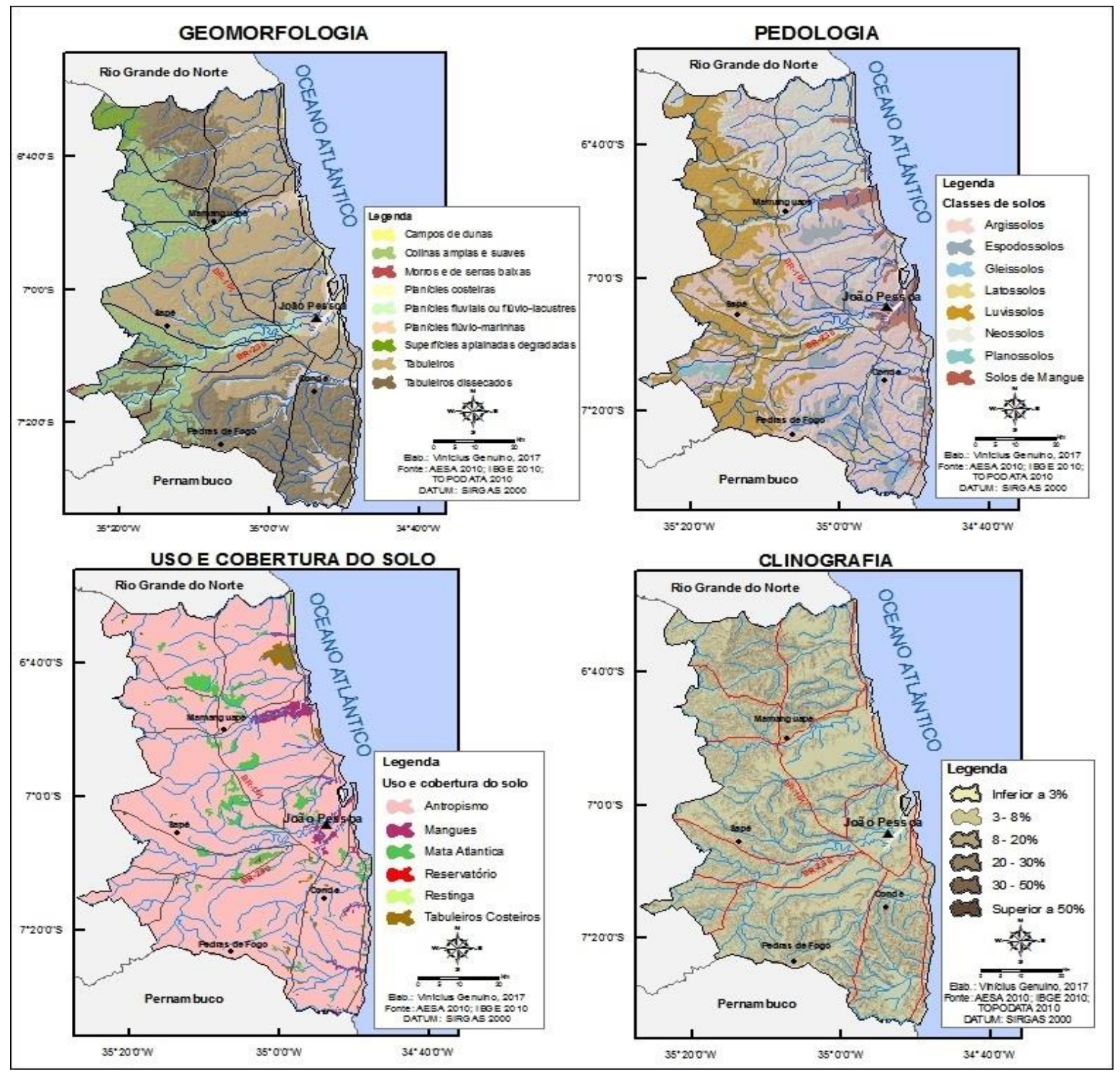

Figura 2 - Mapas temáticos: a) Geomorfologia; b) Pedologia; c) Uso e cobertura do solo; d) Clinografia da Mesorregião da Mata Paraíba - PB.

Partindo dos dados secundários, é possível observar que na geomorfologia predominam os tabuleiros dissecados, fortemente influenciados pela rede de drenagem, variando entre dissecados e pouco 


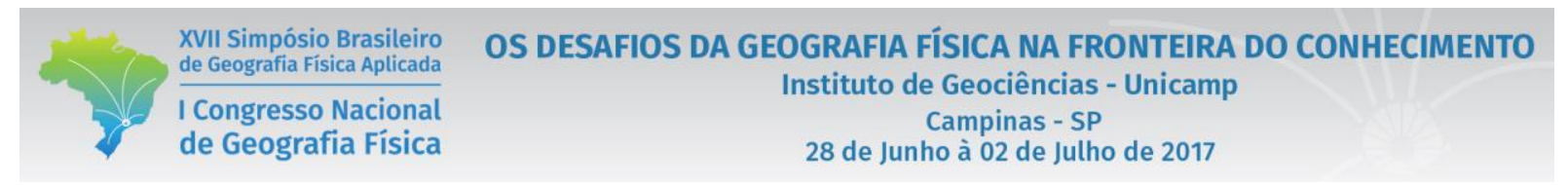

dissecados. Quanto à pedologia, há o predomínio dos argissolos, os quais se caracterizam por serem mais desenvolvidos, inclusive favorecendo a fixação da vegetação. O mapa de uso e cobertura do solo possui uma predominância do antropismo, porém é possível encontrar remanecentes de Mata Atlântica, um dos mais importantes biomas do país. Já a clinografia presente na área, como esperado devido à mesorregião estar presente em zona costeira, exibe predomínio de relevos com declividades inferiores a $8 \%$.

\section{Considerações finais}

A pesquisa, apesar de encontra-se em fase incial, busca compreender o meio ambiente de maneira integrada, postura indispensável para o planejamento socioambiental, pois contempla as informações necessárias para organizar e gerir o território, a fim de estabelecer diretrizes para utilização dos recursos naturais e políticas de ocupação. Com o apoio de técnicas de geoprocessamento, as quais facilitam a integração das informações temáticas, bem como suas análises individuais, é possível estabelecer estratégias de ações e tomadas de decisões em espaços de tempo mais curtos e com maior confiabilidade.

Os próximos passos da pesquisa consistem na avaliação dos aspectos naturais e mensuração da sua fragilidade, como também estudo das condições sociais e econômicas da área, para que com a interrelação dos resultados, se torne possível à construção de diretrizes preventivas e de planejamento e gestão territorial. Desde já é possível afirmar que a urbanização desordenada, e em massa, é um dos fatores que mais implicam dificuldades da gestão, manutenção e proteção dos remanecentes ambientais dessa zona costeira. De acordo com os pré-resultados considera-se que estudos sobre a Zona da Mata são de importância ímpar para o estado da Paraíba, tendo em vista que tal recorte geográfico é propício a elevados graus de fragilidade ambiental. Trata-se ainda da porção territorial com maior ocupação populacional, maior infraestrutura para instalação de empreendimentos e atrativos turísticos, fatos que acarretam maior pressão ambiental.

\section{Bibliografia}

AMARAL, R.; ROSS, J. L. S. - Unidades Ecodinâmicas na análise da fragilidade ambiental do Parque Estadual do Morro do Diabo e entorno, Teodoro Sampaio/SP. GeoUSP - Espaço e Tempo, São Paulo, N²6, pp. $59-78,2009$.

CUNICO, C.; OKA-FIORI, C. - Zoneamento ambiental da bacia hidrográfica do rio Marumbi - PR: Perspectivas para a análise e avaliação das condições sócio-ambientais. Estudos Geográficos, Rio Claro, 6(1): 37-61, 2008 (ISSN 1678-698X) http://cecemca.rc.unesp.br/ojs/index.php/estgeo, 2009. 
DIAS, D. F.; TRENTIN, R.; SCCOTI, A. A. V. - Zoneamento geoembiental para o município da Mata/RS: Síntese das potencialidades e fragilidades. Revista do Departamento de Geografia - USP, Volume 30 (2015), p. 132 a 148.

ROSS, J. L. S. - A análise empírica da fragilidade dos ambientes naturais e antropizados. Revista de Departamento de Geografia/ FFLCH/USP, n 8, 63-73, 1994.

ROSS, J. L. S. - Análises e sínteses na abordagem geográfica da pesquisa para o planejamento ambiental. Revista do Departamento de Geografia/ FFLCH/USP, n 9, p. 65-75.

ROSS, J. L. S. - Da ecodinâmica à fragilidade ambiental: subsídios ao planejamento e gestão ambiental. América Latina: Sociedade e Meio Ambiente / Amália Inês Geraiges de Lemos, Jurandyr Luciano Sanches Ross, Ailton Luchiari (organizadores) - 1.ed. - São Paulo: Expressão Popular; 2008. - (Série Por uma geografia Latinoamericana). p. 67-83. 